\title{
Минералогия циркона и U-Pb возраст метаморфических процессов в гнейсах ТТГ Ингозерского массива (Кольский регион): данные U-Pb SHRIMP датирования
}

\author{
Ниткина Е.А. ${ }^{1}$, Баянова Т.Б. ${ }^{1}$, Лялина Л.М. ${ }^{1}$, Ларионов А.Н. ${ }^{2}$ \\ ${ }^{1}$ Геологический институт КНЦ РАН, Anamumbl,nitkina@geoksc.apatity.ru, bayanova@geoksc.apatity.ru, \\ lyalina@geoksc.apatity.ru \\ ${ }^{2}$ ВСЕГЕИ, С.-Петербург, alexander_larionov@vsegei.sp.ru
}

Аннотация. В кристаллах циркона из гнейсов Ингозерского массива установлена фазовая неоднородность, отвечающая процессам метаморфизма, проявленным в гнейсах комплекса TTГ, а также Th/U отношения, соответствующие таковым для метаморфических цирконов гнейсов. По результатам изотопного U-Pb датирования методом SHRIMP-II (ВСЕГЕИ) получен возраст метаморфизма для амфибол-биотитового гнейса (H-10-07) $2764 \pm 10$ млн. лет и для биотит-амфиболовом гнейсе (Н-10-08) $2739 \pm 12$ млн. лет.

Ключевые слова: Изотопное U-Pb датирование, ТТГ комплексы, минералогия циркона.

\section{Mineralogy of zircon and U-Pb age of metamorphic processes in TTG gneisses of the Ingozero massif complex (Kola region): U-Pb SHRIMP dating}

\author{
Nitkina E.A. ${ }^{1}$, Bayanova T.B. ${ }^{1}$, Lyalina L.M. ${ }^{1}$, Larionov A.N. ${ }^{2}$ \\ ${ }^{1}$ GI KSC RAS, Apatity,nitkina@geoksc.apatity.ru, bayanova@geoksc.apatity.ru,lyalina@geoksc.apatity.ru \\ ${ }^{2}$ VSEGEI, S.-Petersburg, alexander_larionov@vsegei.sp.ru
}

\begin{abstract}
In zircon crystals from the gneisses of the Ingozero massif, a phase inhomogeneity corresponding to the processes of metamorphism manifested in the gneisses of the TTG complex, as well as the Th / U ratios corresponding to those of the metamorphic zircons of the gneisses, was established. According to the results of isotopic U-Pb dating by the SHRIMP-II method (VSEGEI), the age of metamorphism for amphibole-biotite gneiss (H-10-07) is $2764 \pm 10 \mathrm{Ma}$ and for biotite-amphibole gneiss (H-10-08) $-2739 \pm 12$ million years.
\end{abstract}

Key words: $\mathrm{U}-\mathrm{Pb}$ isotope dating, TTG complexes, zircon mineralogy.

\section{Введение}

Ингозерский массив расположен в северной части Беломорского подвижного пояса на СВ Балтийского щита (рис. 1) и представляет собой комплекс тоналит-трондьемит-гранодиоритов (ТТГ) (Объяснительная записка..., 1994; Vetrin et al., 2018). В пределах Ингозерского массива выделены биотитовые, биотит-амфиболовые, амфибол-биотитовые гнейсы, гранитогнейсы, амфиболиты, гранодиориты и пегматиты. Гнейсы являются метаморфизованными и рассланцованными останцами первичных ТТГ пород (Козлов и др., 2006). Для гнейсов Ингозерского массива (Ниткина, Баянова, 2018) точки химических анализов гнейсов ложатся в поля тоналитов и трондьемитов, высокое содержание легких редкоземельных элементов и отсутствие Еu аномалии говорит о происхождение пород из обогащенных источников без существенной роли фракционной.

Последовательность и время проявления эндогенных процессов Ингозерского массива (Козлов и др., 2006) включает следующие этапы: формирование исходных пород для гнейсов $3149 \pm 49$ млн. лет (Bayanova et al., 2016); внедрение даек основных пород; второй этап внедрения тоналитов или метаморфизм и деформации пород, связанные с внедрением даек основных пород $2727 \pm 5-2725 \pm 2$ млн. лет; деформация и рассланцевание пород, происходившие одновременно с внедрением гранитоидных тел $-2697 \pm 9-2667 \pm 7$ млн. лет; внедрение гранитных тел и микроклинизация биотитовых гнейсов $-2615 \pm 8$ млн. лет (Ниткина, Баянова, 2018); образование тел пегматита и послойная микрокоинизация - $2549 \pm 30$ млн. лет; образование пегматитовых и гранитных жил - 1644+/-7 (Ниткина, Баянова, 2018) и образование кварцевых жил. Пробы на минералогические и изотопные U-Pb исследования циркона (методом SHRIMP-II) отобраны из амфибол-биотитовых 


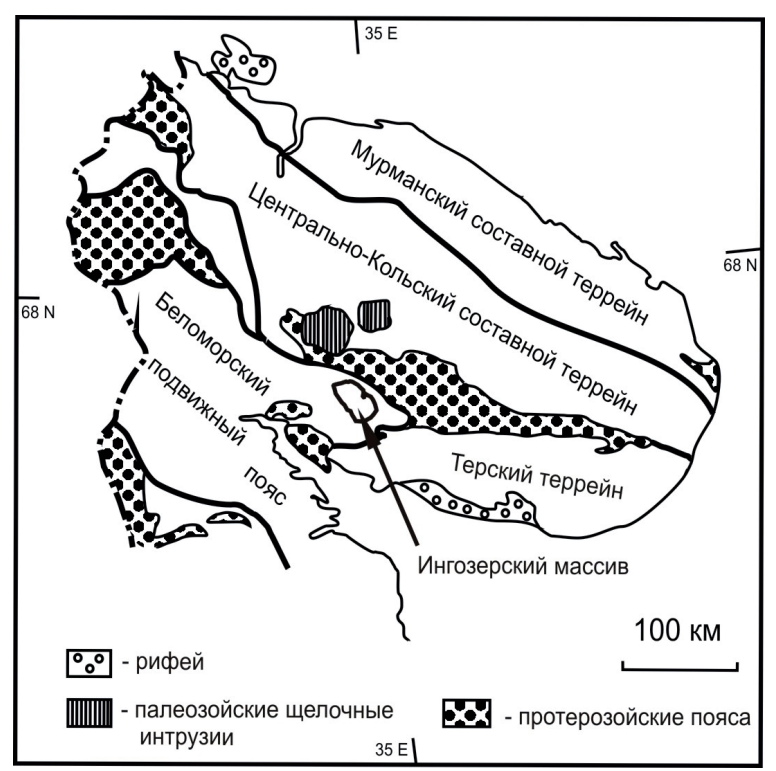

Рис. 1. Схематическая карта Кольского полуострова (Балаганский, 2002).

Fig. 1. Geological map of the Kola Peninsula (Balaganskiy, 2002).

личием темно-коричневых полупрозрачных длиннопризматических кристаллов цирконового типа. Средние размеры - $0.420 \times 0.105$ мм, Ку-4. B BSE и CL выявлена внутрифазовая неоднородность (ядра). Четвёртый представлен темно-коричневыми полупрозрачными изометричными кристаллами со сглаженными гранями со средними размерами - 0.140×0.140 мм, Ку-1. B BSE и CL выявлена внутрифазовая неоднородность (зональность). Пятый включает темно-коричневые длиннопризматические кристаллы гиацинтового типа, средние размеры - 0.245 × 0.09 мм, Ку-2.7. В BSE и CL выявлена внутрифазовая неоднородность (зональность, секториальность).

В биотит-амфиболовом гнейсе (Н-10-08) в мономинеральных фракциях циркона были выделены следующие типы кристаллов циркона (рис. 2 б). Первый объединил темно-коричневые призматические кристаллы гиацинтово-цирконового типа со средними размерами $-0.245 \times 0.110$ мм, Ку-2.2. В BSE и CL выявлена внутрифазовая неоднородность (зональностью, ядра). Второй представлен темно-коричневыми полупрозрачными длиннопризматическими кристаллами игольчатого типа $(\{110\}+\{311\})$, средние размеры - 0.315×0.105 мм, Ку-3. B BSE и CL внутрифазовая неоднородность выявлена слабо и представлена разным свечением участков кристалла. Третий характеризуется наличием темно-коричневых полупрозрачных длиннопризматических кристаллов гиацинтового типа, средние размеры - $0.460 \times 0.12$ мм, Ку-3.8. В BSE и CL выявлена внутрифазовая неоднородность (зональность, секториальность). Четвёртый объединил бледно-розовые прозрачные призматические кристаллы гиацинтово-цирконового типа со средними размерами $-0.200 \times 0.100$ мм, Ку-2. В BSE и CL выявлена внутрифазовая неоднородность, которая представлена тонкой ритмичной зональностью, повторяющей контуры кристалла.

\section{Геохронологическое $\mathrm{U}-\mathrm{Pb}$ датирование циркона}

Изотопные исследования проводилось методом SHRIMP II (чувствительный высокоразрешающий ионный микрозонд второго поколения) в ЦИИ ФГУП «ВСЕГЕИ».

В амфибол-биотитовом гнейсе (Н-10-07) для датирования выбраны (рис. 3а): длинопризматические кристаллы циркона - точки проведения анализа N-10-07_1.1, N-10-07_2.1 и N-10-07_2_1re; изометричные кристаллы циркона - точки проведения анализа N-10-07_3, N-10-07_3.1 re и N-10-07_4. $\mathrm{Ha} \mathrm{U}-\mathrm{Pb}$ диаграмме по фигуративной точке 1 получен конкордантный возраст $2764 \pm 10$ млн. лет, $\mathrm{CKBO}=1.4$ (рис. 4 а, табл. 1). Остальные фигуративные точки дают разброс данных по возрастам от 2650 млн. лет до 2870 млн. лет (рис. 4 a; 5; табл. 1). Th/U отношения составляют 0.32-0.92 (рис. 6, табл. 1). 


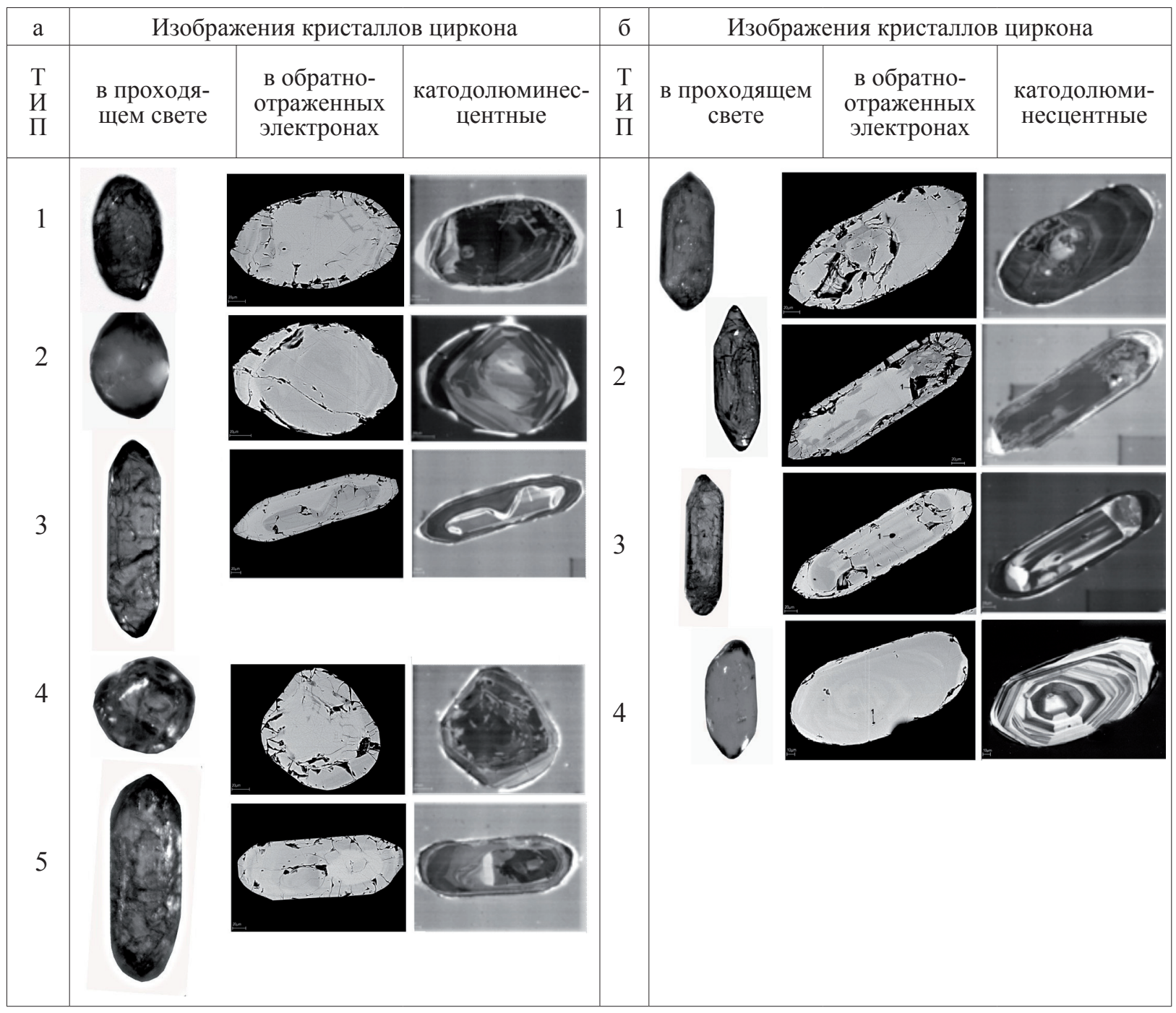

Рис. 2. Фотографии выделенных морфологических типов кристаллов циркона в: а - амфибол-биотитовом гнейсе (Н-10-07); б - биотит-амфиболовом гнейсе (Н-10-08).

Fig. 2. Zircon photo of: a - Amp-Bt gneisses (H-10-07), b - Bt-Amp gneisses (H-10-08).

В биотит-амфиболовом гнейсе (Н-10-08) для датирования выбраны (рис. 3 б): длинопризматические кристаллы циркона - точки проведения анализа N-10-08_1.1, N-10-08_5.1, N-10-08_1.1re; изометричные кристаллы циркона - точки проведения анализа N-10-08_3.1, N-10-08_4.1re, N-10-08_4.1, N-10-08_3.2. На U-Рb диаграмме по 3 фигуративным точкам 1, 2 и 3 построена изохрона с верхним пересечением с конкордией $2739 \pm 12$ млн. лет, СКВО=1.1 (рис. 4 б, табл. 1). Остальные фигуративные точки дают разброс данных по возрастам от 2600 млн. лет до 3070 млн. лет (рис. 4 б; 5; табл. 1). Тh/U отношения составляют от 0.06 до 0.65 (рис. 6, табл. 1).

\section{Въцводы}

Для циркона из гнейсов Ингозерского массива установлена фазовая неоднородность, отвечающая процессам кристаллизации и метаморфизма, проявленным в гнейсах комплекса ТТГ, а также Th/U отношения, характерные для метаморфических цирконов гнейсов (Пыстин, Пыстина, 2018). По результатам изотопного U-Pb датирования методом SHRIMP-II подтверждён возраст проявления метаморфических процессов в гнейсах Ингозерского массива, полученный раннее (Ниткина\&Баянова, 2018): для амфибол-биотитового гнейса (Н-10-07) $2764 \pm 10$ млн. лет, для

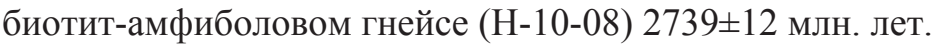


Таблица 1. Изотопные $\mathrm{U}-\mathrm{Pb}$ данные для циркона из гнейсов Ингозерского массива.

Table1. Isotope $\mathrm{U}-\mathrm{Pb}$ zircon data for zircons of the gneisses of the Ingozero massive.

\begin{tabular}{|c|c|c|c|c|c|c|c|c|c|c|c|c|c|c|c|}
\hline Точки & $\begin{array}{c}\% \\
206 \mathrm{~Pb}\end{array}$ & ppm & $\begin{array}{l}\text { ppm } \\
\text { Th }\end{array}$ & ${ }_{206} \mathrm{pb}^{*}$ & $\frac{232}{{ }^{238} \mathrm{Th}}$ & $\begin{array}{l}{ }^{206} \mathrm{~Pb} \\
{ }^{23} \frac{\mathrm{U}}{\mathrm{U}} \\
\text { Age }\end{array}$ & \multicolumn{2}{|c|}{$\begin{array}{l}{ }^{206} \frac{\mathrm{Pb}}{\mathrm{Pb}} \\
\text { Age }\end{array}$} & \multicolumn{2}{|c|}{$\begin{array}{c}\% \\
\text { Dis- } \\
\text { cor- } \\
\text { dant }\end{array}$} & ${ }_{{ }^{23}{ }^{207} \mathrm{P}} \mathrm{Pb}^{*}$ & $\pm \%$ & $\frac{{ }^{206} \mathrm{~Pb}^{*}}{{ }^{23} \mathrm{U}}$ & $\pm \%$ & $\begin{array}{c}\text { err } \\
\text { corr }\end{array}$ \\
\hline \multicolumn{16}{|c|}{ Биотит-амфиболовый гнейс (Н-10-08) } \\
\hline N-10-08_4.1 & 0.35 & 89 & 12 & 40.2 & 0.14 & 2723 & \pm 12 & 2750 & \pm 26 & +1 & 13.84 & 1.7 & 0.526 & 0.5 & 0.32 \\
\hline N-10-08_5.1 & -- & 244 & 30 & 103.1 & 0.13 & 2579 & \pm 26 & 2725 & \pm 11 & +6 & 12.75 & 1.4 & 0.492 & 1.2 & 0.88 \\
\hline N-10-08_4.1re & 0.01 & 2311 & 295 & 572.8 & 0.13 & 1634 & \pm 16 & 2605 & \pm 28 & +42 & 6.96 & 2.0 & 0.288 & 1.1 & 0.54 \\
\hline N-10-08_3.1 & 0.02 & 511 & 30 & 224.0 & 0.06 & 2658 & \pm 23 & 2696 & \pm 6 & +2 & 13.00 & 1.1 & 0.510 & 1.0 & 0.94 \\
\hline N-10-08_3.2 & 0.00 & 255 & 85 & 110.4 & 0.34 & 2634 & \pm 11 & 2700 & \pm 13 & +3 & 12.89 & 0.9 & 0.505 & 0.5 & 0.53 \\
\hline N-10-08_1.1re & 0.86 & 39 & 24 & 15.1 & 0.65 & 2416 & \pm 44 & 3073 & \pm 24 & +26 & 14.62 & 2.6 & 0.455 & 2.2 & 0.82 \\
\hline N-10-08_1.1 & 0.00 & 2446 & 676 & 1173.2 & 0.29 & 2860 & \pm 22 & 2804 & \pm 3 & -2 & 15.19 & 1.0 & 0.558 & 0.9 & 0.98 \\
\hline \multicolumn{16}{|c|}{ Амфибол-биотитовый гнейс (Н-10-07) } \\
\hline N-10-07_2_1re & 0.00 & 1340 & 659 & 611.9 & 0.51 & 2748 & \pm 22 & 2765 & \pm 4 & +1 & 14.12 & 1.0 & 0.532 & 1.0 & 0.96 \\
\hline N-10-07_3.1 & -- & 2049 & 9 & 868.1 & 0.00 & 2585 & \pm 11 & 2648 & \pm 7 & +3 & 12.21 & 0.6 & 0.493 & 0.5 & 0.78 \\
\hline N-10-07_2.1 & 0.01 & 78 & 25 & 36.9 & 0.33 & 2824 & \pm 40 & 2761 & \pm 15 & -3 & 14.57 & 2.0 & 0.550 & 1.7 & 0.88 \\
\hline N-10-07_1.1 & 0.10 & 206 & 182 & 92.2 & 0.92 & 2707 & \pm 28 & 2778 & \pm 12 & +3 & 13.97 & 1.5 & 0.522 & 1.3 & 0.86 \\
\hline N-10-07_3.1re & 0.17 & 93 & 29 & 40.3 & 0.32 & 2630 & \pm 36 & 2811 & \pm 20 & +8 & 13.76 & 2.1 & 0.504 & 1.7 & 0.80 \\
\hline N-10-07_4.1 & 0.07 & 73 & 35 & 34.3 & 0.50 & 2828 & \pm 38 & 2874 & \pm 16 & +2 & 15.63 & 1.9 & 0.551 & 1.7 & 0.86 \\
\hline
\end{tabular}

Ошибки приведены на уровне $1 \delta ; \mathrm{Pbc}$ and $\mathrm{Pb} *$ общий и радиогенный свинец. соответственно

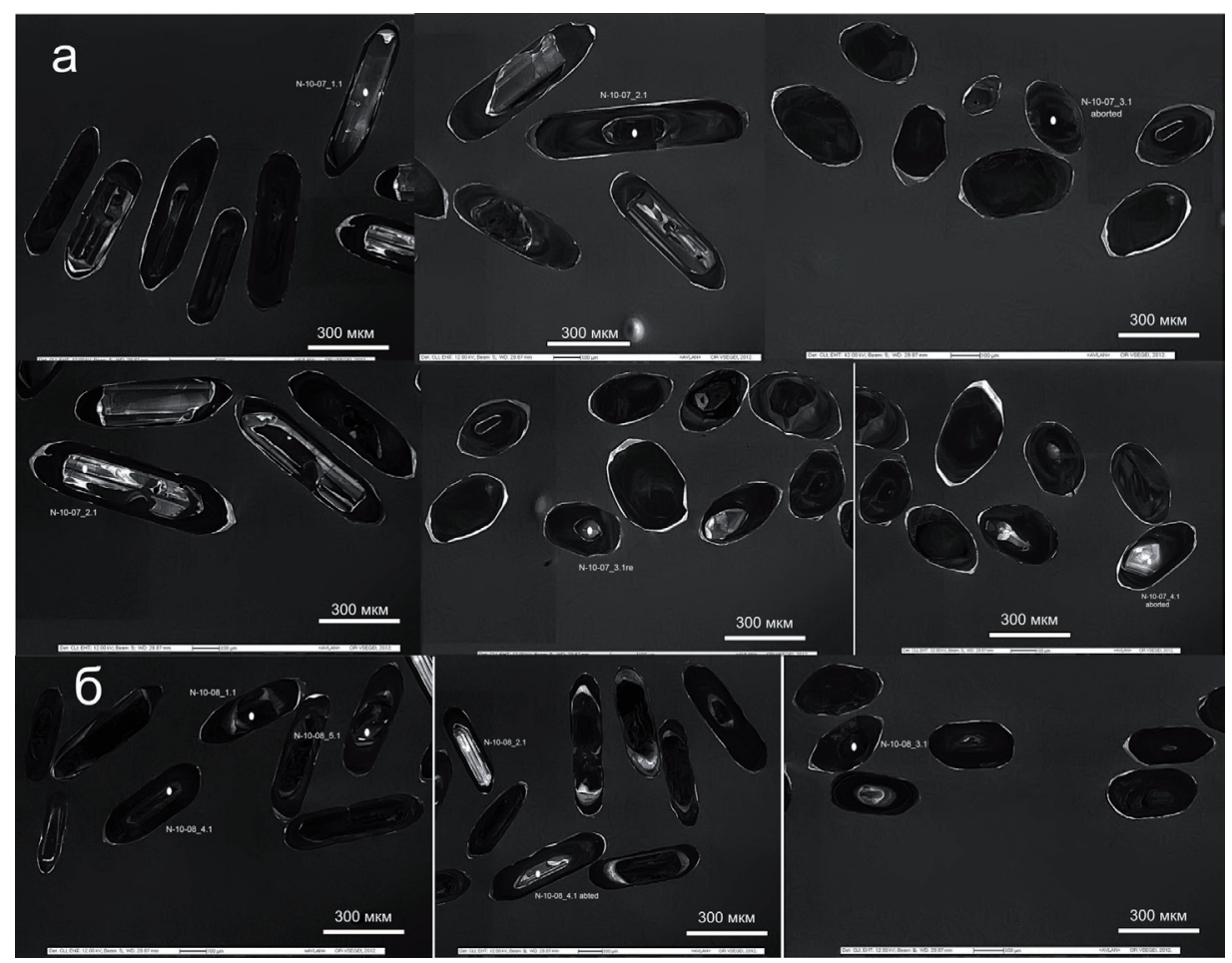

Рис. 3. Катодолюминесцентные изображения кристаллов циркона и точки датирования для: а - амфиболбиотитового гнейса (Н-10-07); б - биотит-амфиболового гнейса (Н-10-08).

Fig. 3. CL images of zircon and SHRIMP-II points for: a - Amp-Bt gneisses (H-10-07), b - Bt-Amph gneisses (H-10-08).

\section{Благодарности}

Авторы выражают искреннюю благодарность директору ГИ КНЦ РАН Козлову Н.Е. и Козловой Н.Е. за консультации. 

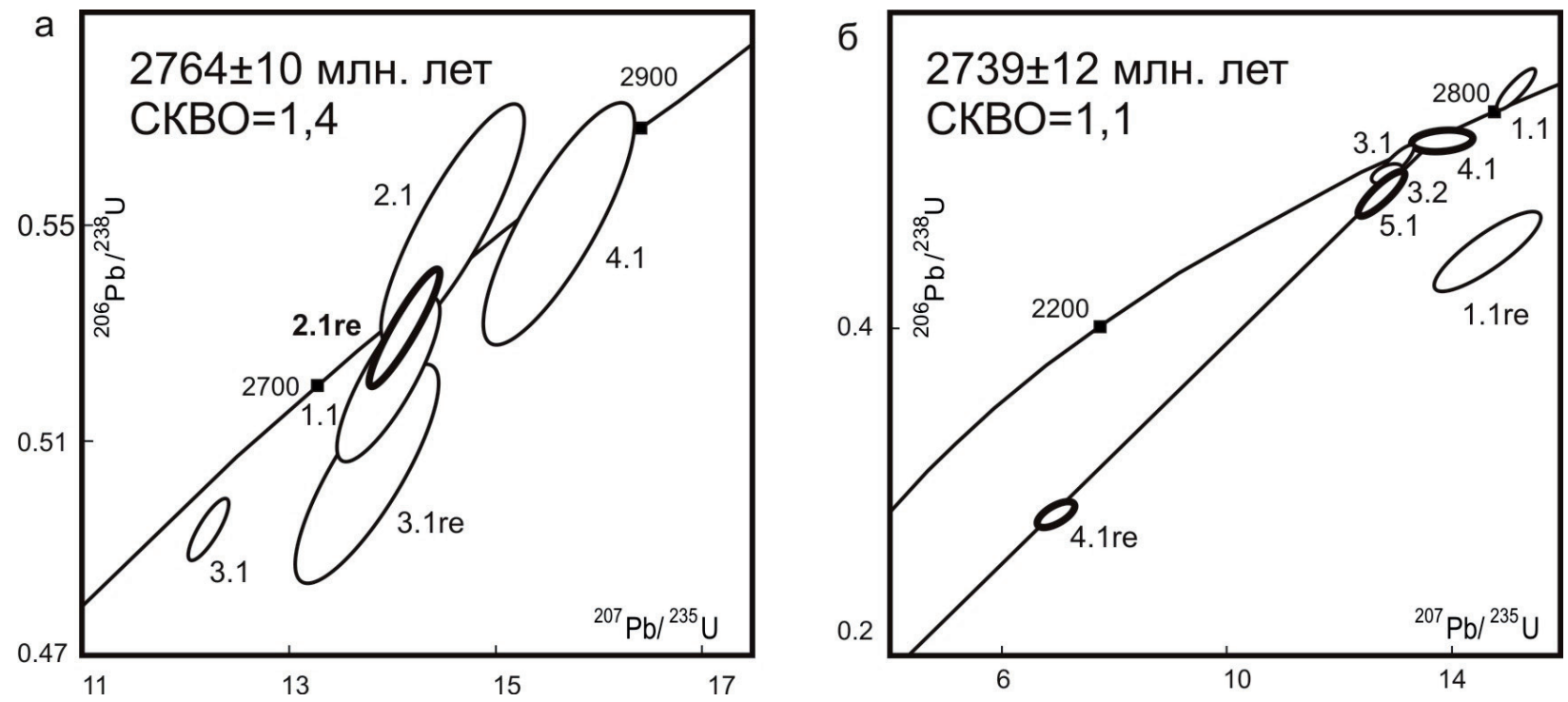

Рис. 4. Изотопная U-Pb диаграмма для циркона из: а - амфибол-биотитового гнейса (H-10-07), б - биотитамфиболового гнейса (Н-10-08).

Fig. 4. U-Pb diagram for zircon: a - Amp-Bt gneisses (H-10-07), $\mathrm{b}$ - Bt-Amp gneisses (H-10-08).

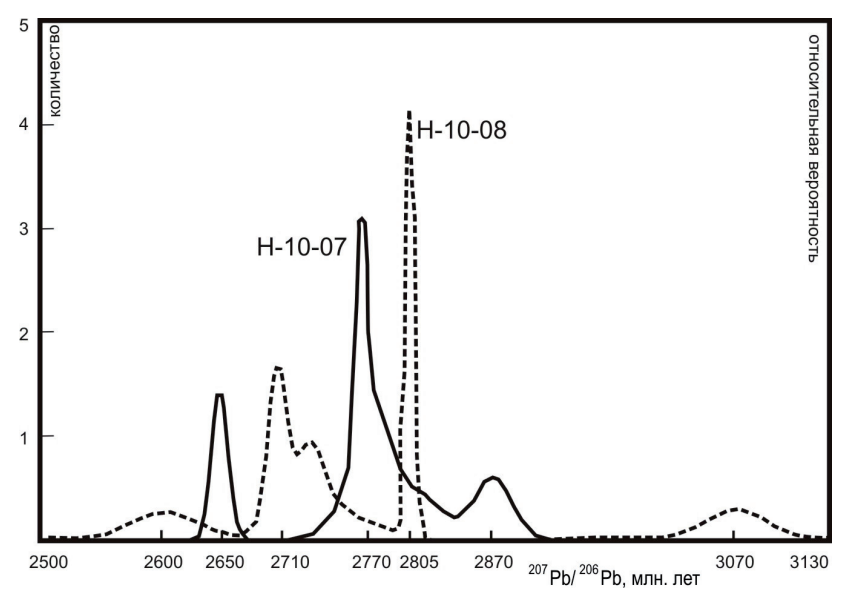

Рис. 5. Распределение возрастов циркона в амфиболбиотитовом и биотит-амфиболовом гнейсах.

Fig. 5.Probability of zircon ages of Amp-Bt gneisses and Bt-Amp gneisses.

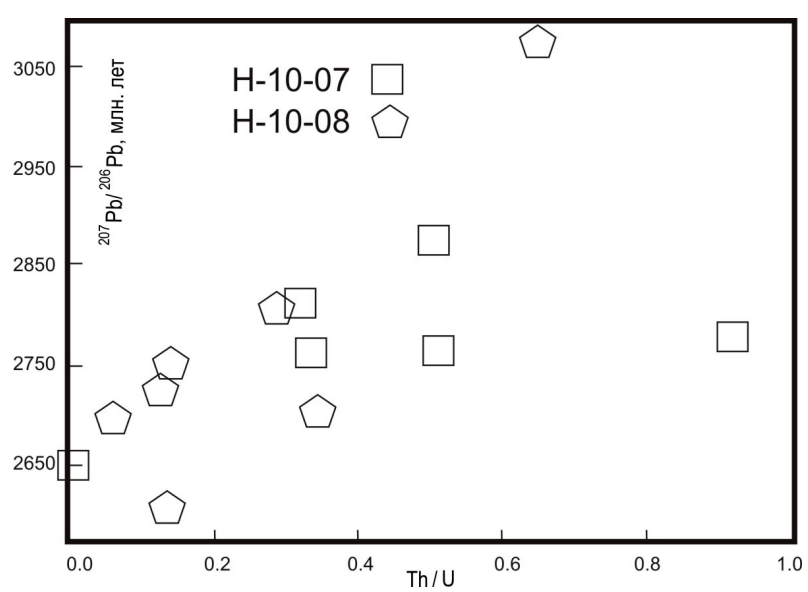

Рис. 6. Th/U отношения для циркона из амфиболбиотитового и биотит-амфиболового гнейсов.

Fig. 6. Th/U ratios for zircon of Amp-Bt gneisses and Bt-Amp gneisses.

Работа выполнена по теме НИР 0226-2019-0052.

\section{Литература}

1. Балаганский В.В. Главные этапы тектонического развития северо-востока Балтийского щита в палеопротерозое. Автореф. дисс. д.г.-м.н. СПб. 2002. 32 с.

2. Козлов Н.Е., Сорохтин Н.О., Глазнев В.Н., Козлова Н.Е., Иванов А.А., Кудряшов Н.М., Мартынов Е.В., Тюремнов В.А., Матюшкин А.В., Осипенко Л.Г. Геология архея Балтийского щита. СПб. Изд-во: Наука. 2006. 329 C.

3. Ниткина Е.А., Баянова Т.Б. Изотопно-геохронологическое изучение пород Ингозерского массива (Кольский полуостров) // Вестник Мурманского государственного университета. 2018. Т. 21. № 1. С. 51-60. https://oi. org/10.21443/1560-9278-2018-21-1-51-60.

4. Объяснительная записка к геологической карте северо-восточной части Балтийского щита масштаба 1:500 000 / Ред. Ф.П. Митрофанов. Апатиты. Изд-во: КНЦ РАН. 1994. 95 С.

5. Пыстина Ю.И., Пыстин А.М. Распределение U и Тh в цирконах метаморфических пород и гранитоидов севера Урала // 12-я Межрегиональная научно-практическая конф. Уфа. 21-23 мая 2018 г. Спб. Изд-во: Свое издательство. 2018. С. 294-299. 